\title{
LA ESTABILIDAD EN EL EMPLEO Y LA REINSTALACIÓN OBLIGATORIA. APARTADO A DEL ARTÍCULO 123 CONSTITUCIONAL MEXICANO*
}

\author{
STABILITY IN EMPLOYMENT AND COMPULSORY \\ RE-INSTALLATION. PARAGRAPH (A) OF MEXICAN \\ CONGRESSIONAL ARTICLE 123
}

\author{
STABILITÉ DE L'EMPLOI ET RÉ-INSTALLATION \\ OBLIGATOIRE. PARAGRAPHE A) DE L'ARTICLE 123 \\ DU CONGRÈS MEXICAIN
}

\section{Luis Enrique Morales ArRedONDO*}

\begin{abstract}
RESUMEN: La estabilidad en el empleo es quizá el corolario de los derechos de los trabajadores, fruto de grandes luchas sociales en la historia del derecho del trabajo, pues antes de buscar la obtención de salarios justos, jornadas de trabajo de 8 horas y otras condiciones favorables de trabajo, todo operario en principio busca sin duda la permanencia en el puesto de trabajo; por ello, el presente trabajo a partir de un método deductivo presenta una investigación sobre la estabilidad en el empleo en el derecho del trabajo mexicano, partiendo de los criterios aplicables de la Corte Interamericana de Derechos Humanos, pasando por la Constitución Política de los Estados Unidos Mexicanos, y particularizando el estudio en la Ley Federal del Trabajo.

Lo anterior para confrontar el derecho, sometido a nuestro análisis, con la reinstalación obligatoria luego de un despido injustificado, y con ello poner en evidencia las deficiencias legislativas en nuestro derecho del trabajo, proponiendo soluciones concretas tendientes a proporcionar una verdadera protección de la clase trabajadora frente a las relaciones de trabajo forzadas. Esto, a la luz del derecho patronal para ser eximido
\end{abstract}

* Recibido el 2 de febrero de 2021 y aceptado para su publicación el 15 de marzo de 2021.

** Licenciado en derecho por la Universidad Nacional Autónoma de México; especialista en derecho laboral por la Unidad de Posgrado de la Facultad de Derecho de la UNAM. 
de la obligación de cumplir con el contrato de trabajo y reinstalar a sus trabajadores despedidos de forma injustificada y de los procedimientos legales para la obtención de la exención que aquí se trata.

Una vez analizados los puntos antes citados, el desarrollo del presente trabajo nos permitirá arribar a las conclusiones descritas en los siguientes párrafos:

La estabilidad en el empleo es un derecho de los trabajadores para conservar su trabajo durante todo el tiempo pactado o determinado en la ley para la duración de la relación de trabajo puede perderse sólo si existe una causa legalmente justificada para la recisión sin responsabilidad para el patrón. Por tanto, este derecho se adquiere desde el momento mismo del nacimiento de la relación de trabajo.

La reinstalación en el puesto de trabajo, de los operarios injustificadamente despedidos, es un medio de reparación a la violación del derecho a la estabilidad en el empleo por medio del cual se restablece el derecho violado y, como consecuencia las condiciones de trabajo, con lo cual se brinda a los trabajadores continuidad en su relación de trabajo y en los beneficios derivados de ella.

La reinstalación de los trabajadores despedidos de forma injustificada es por regla general obligatoria, y por excepción el patrón tendrá derecho a ser eximido de la obligación de cumplir con el contrato de trabajo en los supuestos expresamente previstos en el artículo 49 de la Ley Federal del Trabajo, conmutándose dicha obligación con los pagos compensatorios previstos en el artículo 50 de dicha ley.

Consideramos necesario invertir los alcances de los supuestos normativos contenidos en el artículo 49 de la Ley Federal del Trabajo para constituir como regla general el derecho patronal a ser eximido de la obligación de cumplir con el contrato de trabajo, al considerar casos de excepción en los cuales la reinstalación en el puesto de trabajo deba ser obligatoria.

El procedimiento jurídico por medio del cual el patrón puede ser eximido de la obligación de cumplir con el contrato de trabajo, es el incidente al cual denominamos "incidente de exención y pago compensatorio de la obligación de cumplimiento de contrato", y no así por medio de la insumisión al arbitraje, el no acatamiento de la resolución ni el procedimiento paraprocesal contenidos en la Ley Federal del Trabajo.

Palabras clave: estabilidad, empleo, reinstalación, patrón, trabajador.

ABSTRACT: Stability in employment is perhaps the corollary of workers' rights resulting from great social struggles in the history of labour law, 
because before seeking fair wages, 8-hour working hours and other favourable working conditions, every operator in principle certainly seeks to remain in the workplace; therefore, this work based on a deductive method presents an investigation into the stability in employment in Mexican labour law, based on the applicable criteria of the Inter-American Court of Human Rights, through the Political Constitution of the United Mexican States and particularizing the study in the Federal Labour Law.

This is to confront the right under our analysis with mandatory reinstallation after unjustified dismissal and thereby highlight the legislative deficiencies in our labour law, proposing concrete solutions aimed at providing true protection of the working class from forced labour relations. This, in the light of the employer's right to be exempted from the obligation to comply with the employment contract and to reinstate its dismissed workers unjustifiably and the legal procedures for obtaining the exemption in comment.

Once the above points have been analyzed, the development of this work will allow us to reach the following conclusions:

Stability in employment is a right of workers to keep their work for as long as agreed or determined by law for the duration of the employment relationship, and may lose it only if there is a legally justified cause for rescission without liability for the employer. Therefore, this right is acquired from the very moment of the birth of the employment relationship.

The re-installation in the workplace of unjustifiably dismissed operators is a means of redressing the violation of the right to stability in employment by which the violated right is restored and because of working conditions, providing workers with continuity in their employment relationship and the benefits derived from it.

The reinstatement of unjustifiably dismissed workers is generally mandatory and by way of exception the employer shall be entitled to be exempted from the obligation to comply with the employment contract in the cases expressly provided for in article 49 of the Federal Labour Law, with that obligation being commuted to the compensatory payments provided for in article 50 of that law.

We consider it necessary to reverse the scope of the regulatory assumptions contained in article 49 of the Federal Labour Law in order to constitute as a general rule the employer's right to be exempted from the obligation to comply with the employment contract, considering cases of exception in which the reinstallation in the workplace must be mandatory. 
The legal procedure by which the employer may be exempted from the obligation to comply with the employment contract is the incident that we call "incident of exemption and compensatory payment of the obligation to comply with contract" and not by insubmissing to arbitration, noncompliance with the resolution or the paraprocess procedure contained in the Federal Labour Law.

Keywords: stability, employment, reinstallation, pattern, worker.

RÉSUMÉ: La stabilité de l'emploi est peut-être le corollaire des droits des travailleurs résultant de grandes luttes sociales dans l'histoire du droit du travail, parce qu'avant de chercher des salaires équitables, des heures de travail de 8 heures et d'autres conditions de travail favorables, chaque opérateur cherche en principe certainement à rester sur le lieu de travail; par conséquent, ce travail basé sur une méthode déductive présente une enquête sur la stabilité de l'emploi dans le droit du travail mexicain, basée sur les critères applicables de la Cour interaméricaine des droits de l'homme, à travers la Constitution politique des États-Unis et en particulier l'étude dans le droit fédéral du travail.

Il s'agit de confronter le droit dans notre analyse à la ré-installation obligatoire après licenciement injustifié et ainsi de mettre en évidence les lacunes législatives de notre droit du travail, en proposant des solutions concrètes visant à assurer une véritable protection de la classe ouvrière contre les relations de travail forcé. Ceci, à la lumière du droit de l'employeur d'être exempté de l'obligation de se conformer au contrat de travail et de réintégrer injustifiablement ses travailleurs licenciés et des procédures légales d'obtention de l'exemption en commentaire.

Une fois les points ci-dessus analysés, l'évolution de ces travaux nous permettra de tirer les conclusions suivantes:

La stabilité de l'emploi est un droit des travailleurs de conserver leur travail aussi longtemps que convenu ou déterminé par la loi pour la durée de la relation d'emploi, et ne peut le perdre que s'il existe une cause juridiquement justifiée de récision sans responsabilité pour l'employeur. Par conséquent, ce droit est acquis dès le moment même de la naissance de la relation d'emploi.

La ré-installation sur le lieu de travail d'opérateurs licenciés de manière injustifiée est un moyen de remédier à la violation du droit à la stabilité de l'emploi par lequel le droit violé est rétabli et, en raison des conditions de travail, de fournir aux travailleurs une continuité dans leur relation d'emploi et les avantages qui en découlent. 
La réintégration des travailleurs licenciés de manière injustifiée est généralement obligatoire et, à titre d'exception, l'employeur a le droit d'être exempté de l'obligation de se conformer au contrat de travail dans les affaires expressément prévues à l'article 49 de la loi fédérale sur le travail, cette obligation étant commuée en paiements compensatoires prévus à l'article 50 de cette loi.

Nous estimons nécessaire d'inverser la portée des hypothèses réglementaires contenues à l'article 49 de la loi fédérale sur le travail afin de constituer en règle générale le droit de l'employeur d'être exempté de l'obligation de se conformer au contrat de travail, compte tenu des cas d'exception dans lesquels la réinstallation sur le lieu de travail doit être obligatoire.

La procédure légale par laquelle l'employeur peut être exempté de l'obligation de se conformer au contrat de travail est l'incident que nous appelons «incident d'exemption et de paiement compensatoire de l'obligation de se conformer au contrat» et non par insoumis à l'arbitrage, non-respect de la résolution ou de la procédure de paraprocesseur contenue dans la loi fédérale sur le travail.

Mots-clés: stabilité, emploi, réinstallation, modèle, travailleur.

SUMARIO: I. Introducción. II. La estabilidad en el empleo. III. Liberación de la obligación de reinstalar. IV. Los pagos compensatorios de la obligación de reinstalar. V. La reinstalación obligatoria. VI. Procedimiento para eximir al patrón de la obligación de reinstalar. VII. Conclusiones. VIII. Bibliografía.

\section{INTRODUCCIÓN}

1 odo trabajador entrega su fuerza humana de trabajo con el objeto de obtener una mejor calidad de vida para sí y para su familia. En la búsqueda a largo plazo de una vejez digna, el factor más importante para obtenerla es la permanencia en el trabajo durante los años productivos para la generación de derechos protectores de la vida en cesantía. Por ello, el derecho a la estabilidad en el empleo es sin duda el pilar en donde descansa la expectativa de una vejez tranquila y se convierte en una de las prerrogativas fundamentales en toda relación de trabajo, pues es a través de la permanencia en el empleo como de acuerdo con nuestras leyes se adquieren mejores derechos laborales a largo plazo. 
En ese orden de ideas, el estudio de la estabilidad en el empleo en la doctrina laboral mexicana ha tomado gran fuerza en la última década, sobre todo a partir de las reformas a la Ley Federal del Trabajo de 2012, las reformas constitucionales de 2017, y por supuesto, de las reformas a la ley secundaria de 2019, pues han sido trascendentes en la estabilidad en el empleo y la violación a ese derecho por medio del despido injustificado. La forma de tratar el tema desde el ámbito legislativo ha ocasionado diversas opiniones en el mundo académico, todas de gran relevancia para nuestro estudio.

Por ello, el presente trabajo presenta al lector el análisis de la estabilidad en el empleo desde un enfoque teórico-práctico, a la luz de la trascendencia de este derecho no sólo para los trabajadores, sino también para los patrones y en general en toda relación de trabajo. Estudiaremos también una de las formas de reparación a su violación; es decir la reinstalación obligatoria y sus efectos en las relaciones laborales, así como los procedimientos para eximir a la patronal de la obligación de cumplir con el contrato de trabajo, con el objeto de brindar a nuestro lector un panorama general de las deficiencias legislativas en el derecho del trabajo mexicano, en el marco de la protección de los derechos laborales de la clase obrera.

Finalmente, y con un enfoque objetivo, proponemos las posibles soluciones a las conflictivas legales respecto del tema materia de nuestro estudio, con el fin de hacer efectiva la protección de los derechos de los trabajadores en un contexto general de prerrogativas combinadas entre sí, capaces no sólo de contener mandatos imperativos plasmados en legislaciones vigentes, sino de brindar una eficaz protección tangible a la clase trabajadora durante las relaciones de trabajo, sin dejar de buscar el equilibrio entre los factores de la producción y la justicia social como fin último del derecho del trabajo.

\section{LA ESTABILIDAD EN EL EMPLEO}

Desde el punto de vista jurídico, la estabilidad en el empleo es el derecho reconocido por el Estado a la clase trabajadora en la fracción XXII del apartado A del artículo 123 de la Constitución Política de los Estados Unidos Mexicanos, para no ser despedido de su trabajo si no por causa legalmente justificada; es por tanto, el derecho de los operarios para conservar su empleo por todo el tiempo de duración de la relación laboral, el cual sólo pueden perderlo por incurrir en una falta grave determinada por el legislador para justificar la rescisión de la relación de trabajo, o por verificarse una hipótesis normativa para su terminación. 
El doctor José Dávalos Morales ha sostenido que la estabilidad en el empleo

...es la seguridad jurídica del trabajador a permanecer en su empleo por todo el tiempo que éste desee conservarlo, el cual sólo puede perder por una conducta u omisión grave establecida en la legislación laboral como una causa especifica de rescisión de la relación laboral; o bien, porque se verifique alguna causa ajena a la voluntad de los sujetos de la relación de trabajo que haga imposible su continuación. ${ }^{1}$

En consecuencia, la estabilidad en el empleo permite a los trabajadores tener la certeza jurídica de que la duración de su relación de trabajo no estará sujeta al capricho del patrón, pues en principio las relaciones laborales deben perdurar conforme a lo establecido en la Ley Federal del Trabajo o en el contrato laboral; verbigracia, por tiempo indeterminado o determinado, por obra determinada, por temporada, etc., lo cual posibilita al trabajador llevar una vida estable con proyectos a futuro; sin olvidar los efectos producidos por la estabilidad en el empleo respecto a la seguridad social de los operarios, sobre todo en el tema de pensiones.

En atención al derecho a la estabilidad en el empleo, la duración de las relaciones de trabajo no está sujeta a la voluntad de las partes, pues no es jurídicamente válido pactarla en forma contraria a lo consignado en la Ley Federal del Trabajo, ordenamiento legal en el cual se establece como principio rector de la temporalidad de las relaciones laborales, el tiempo indeterminado; a decir de Luis María Aguilar Morales: "la temporalidad del contrato individual de trabajo, al contrario de lo que sucede con el colectivo se somete a reglas precisas que limitan la voluntad de las partes". 2

La legislación laboral mexicana, como casos de excepción, reconoce las relaciones de trabajo por tiempo determinado, por obra determinada, por temporada, para la inversión de capital determinado, de capacitación inicial entre otras, en cuyos supuestos su temporalidad limitada es procedente siempre y cuando la naturaleza de los servicios prestados lo justifique, pero en ninguna de ellas se autoriza al patrón a rescindirlas sin justificación legal alguna antes del vencimiento del plazo fijado; por ello, en esos casos el derecho a la esta-

1 Dávalos Morales, José, Tópicos laborales. Derecho individual, colectivo y procesal. Trabajos especificos. Seguridad social. Perspectivas, $4^{\text {a }}$ ed., México, Porrúa, 2006, p. 494.

2 Ibidem, p. 44. 
bilidad en el empleo está sujeto a la temporalidad de la relación de trabajo; es decir, a tiempo u obra determinada.

Además de no estar sujeta la duración de la relación de trabajo al arbitrio del patrón, la estabilidad en el empleo constituye una garantía para la clase trabajadora mientras preste sus servicios personales subordinados para no ser despedido de su trabajo si no existe una causa justa meritoria de la rescisión laboral; por tanto, la estabilidad en el empleo tiene un alcance dicotómico: por un lado constriñe la temporalidad de la relación laboral a lo establecido en la ley laboral y no la sujeta a la voluntad de las partes, y por el otro es garante de la permanencia de la clase obrera en el puesto de trabajo.

La estabilidad en el empleo "es la columna vertebral del derecho del trabajo" presencia del derecho a la estabilidad en el empleo, aún en las relaciones de trabajo por tiempo fijo, pues en este supuesto el trabajador debe tener la certeza de su permanencia en su trabajo por todo el tiempo por el cual fue contratado, sin ser óbice incluso el periodo de prueba o capacitación inicial, pues aún en dichos supuestos el trabajador goza de estabilidad durante esos periodos, pues no debe ser despedidos sin justa causa antes de concluir el periodo de prueba o capacitación inicial.

Ahora bien, gran parte de la doctrina en la materia ha relacionado a la estabilidad en el empleo de forma íntima con la obligatoriedad patronal de reinstalar en su puesto de trabajo a los trabajadores injustificadamente despedidos, como lo analizaremos más adelante; sin embrago, también se ha reconocido a la estabilidad laboral como un derecho relativo del cual carecen los trabajadores señalados en el artículo 49 de la Ley Federal del Trabajo. La mayoría de los estudiosos del derecho del trabajo han negado la estabilidad laboral a los trabajadores en comento, y la ubican para quienes deben gozar de ella como un derecho adquirido sólo con el paso del tiempo.

El artículo 49 de la Ley Federal del Trabajo concede al patrón el derecho de ser eximido para reinstalar a los trabajadores injustificadamente despedidos y pretendan ser reinstalados en su puesto de trabajo, siempre y cuando se trate de trabajadores con una antigüedad menor a un año en la fuente de trabajo o de operarios cuyas funciones o servicios prestados deban realizarse en contacto directo y permanente con el patrón, así como de trabajadores de confianza, de trabajadores del hogar y eventuales, lo cual será materia de análisis en el presente trabajo en líneas más adelante. Por ahora, sólo hemos mencionado el contenido normativo.

\section{Ibidem, p. 67.}


El doctor Arturo Fernández Arras sostiene: "el derecho a la estabilidad en el empleo no es absoluto, pues éste se flexiona únicamente en los casos expresamente señalados en el artículo 49 de la Ley Federal del Trabajo, en cuyos supuestos el patrón puede negarse a reinstalar al trabajador despedido". ${ }^{4}$ Sin embargo, el derecho a la estabilidad en el empleo no debe entenderse como el derecho del trabajador despedido injustificadamente a ser reinstalado en su empleo, sino como el derecho a no ser despedido sin justa causa.

Por tanto, los casos señalados en el artículo 49 de la Ley Federal del Trabajo no deben considerarse como hipótesis normativas en las cuales se flexibilice el derecho a la estabilidad en el empleo, pues dicha disposición legal se refiere sólo a la flexibilidad de la obligación patronal al restablecimiento de la estabilidad laboral vulnerada, pues como lo refiere la Segunda Sala de la Suprema Corte de Justicia de la Nación, la disposición legal al empleador "lo sujeta a la condición de pagar una cantidad determinada por la responsabilidad de su decisión de no reinstalar al trabajador". ${ }^{5}$

En efecto, el derecho a la estabilidad en el trabajo está restringido pero por los supuestos normativos contenidos en el artículo 47 de la Ley Federal del Trabajo, pues en él se establecen las causas por las cuales el trabajador puede ser despedido sin responsabilidad para el patrón; esto es, si el operario incurre en alguno de los supuestos normativos contenidos en dicho precepto, pierde el derecho a la estabilidad en el empleo — derecho de permanencia en su puesto de trabajo- por lo cual su relación de trabajo concluirá de forma anticipada al plazo fijado por la legislación o por el contrato de trabajo sin responsabilidad para el patrón.

Así también la Corte Interamericana de Derechos Humanos ha dicho:

Cabe precisar que la estabilidad laboral no consiste en una permanencia irrestricta en el puesto de trabajo, sino de respetar este derecho, entre otras medidas, otorgando debidas garantías de protección al trabajador a fin de que, en caso de despido se realice éste bajo causas justificadas, lo cual implica que el empleador acredite las razones suficientes para imponer dicha sanción con las debidas garantías, y frente a ello el trabajador pueda recurrir

4 Fernández Arras, Arturo, Selección de temas. Derecho individual del trabajo, México, Barra Nacional de Abogados, 2006, p. 54.

5 Tesis 2a./J. 15/2018 (10a.), Semanario Judicial de la Federación y su Gaceta, décima época, t. I, libro 51, febrero de 2018, p. 478. 
tal decisión ante las autoridades internas, quienes verifiquen que las causales imputadas no sean arbitrarias o contrarias a derecho. ${ }^{6}$

Por ello, no debe entenderse a la estabilidad en el empleo como el derecho de los trabajadores a ser reinstalados en su puesto de trabajo después de un despido injustificado, sino como el derecho de permanencia en la fuente de trabajo, el cual sólo puede vedarse mediante el despido justificado fundado y motivado en alguna causa prevista legalmente; es decir, al amparo del derecho de la estabilidad en el trabajo, ningún trabajador debe ser despedido de forma injustificada, en consecuencia todos los trabajadores gozan del derecho a la estabilidad en el empleo cuya excepción sólo se verifica ante una causa justa de separación.

En ese contexto, y como todos los derechos reconocidos en nuestra carta magna y en tratados internacionales, la prerrogativa a la estabilidad en el empleo no debe concebirse como un derecho absoluto, pero se debe ser cuidadoso para no confundir su contenido y restricciones, con sus medios de reparación cuando resulte vulnerado, ni tampoco con el derecho del patrón para ser eximido de reparar su violación mediante la reincorporación del trabajador injustificadamente despedido, pues aún en esa hipótesis no se le exime a la parte patronal de la responsabilidad jurídica para remediar su falta.

Por lo anterior, la estabilidad en el empleo no es un derecho de los trabajadores adquirido con el paso del tiempo y mucho menos un derecho del cual carezcan los operarios de nuevo ingreso, sino se adquiere desde el inicio de la relación de trabajo, bien por la prestación de los servicios personales subordinados, bien por la celebración de un contrato de trabajo; en atención a esto, consideramos inexacto lo sostenido por Carlos de Buen Urbina, al señalar: "En suma, el trabajador tendrá que ganarse el derecho a la estabilidad por el transcurso del tiempo, cuya duración dependería de la complejidad de su trabajo". 7

En otro orden de ideas, la violación al derecho de la estabilidad en el empleo, cometida por el patrón mediante una rescisión injustificada de la relación de trabajo - despido injustificado- genera el derecho constitucionalmente reconocido al trabajador, para exigir de su empleador la reparación

6 Lagos del Campo vs. Perú, Corte Interamericana de Derechos Humanos, sentencia, excepciones preliminares, de fondo, reparaciones y costas, serie C, no. 340, Costa Rica, 31 de agosto de 2017, párrafo 150.

7 De Buen Urbina, Carlos, Análisis de la Ley Federal del Trabajo. Comentarios y jurisprudencia, México, Porrúa, 2017, p. 100. 
del derecho violado mediante el ejercicio de una acción legal a elección del operario, bien para demandar el pago de una indemnización correspondiente a 3 meses de salario, o para reclamar la reinstalación en su puesto de trabajo. En ambos casos podrá también demandar el pago de salarios vencidos y en su caso de intereses.

De esta manera, la fracción XXII del apartado A del artículo 123 constitucional antes citado, reconoce dos medios jurídicos de reparación a la violación cometida al derecho de la estabilidad en el empleo: el primero se refiere al pago resarcitorio de una indemnización por el importe de 3 meses de salario, cuyos efectos generan el rompimiento definitivo de la relación de trabajo; y el segundo mediante el restablecimiento del derecho vulnerado, cuya implicación conlleva la continuación de la relación laboral entre trabajador y patrón, así como el restablecimiento de las condiciones de trabajo.

El reclamo de la indemnización de 3 meses de salario, arriba señalada, implica la aceptación obrera de la rescisión de la relación de trabajo a cambio de un pago resarcitorio derivado de la responsabilidad patronal por la vulneración al derecho a la estabilidad en el empleo; sin embargo, aun cuando ello es materia de un vasto análisis, el presente trabajo no tiene por objeto profundizar en el estudio de dicha indemnización, sólo hacemos referencia de ella como uno de los medios de reparación constitucionalmente reconocidos por la violación cometida mediante el despido injustificado.

Por su parte, la reinstalación del trabajador en su puesto de trabajo, llevada a cabo como consecuencia de la acción legal intentada derivada de un despido injustificado, es el acto jurídico mediante el cual se le restablece materialmente su derecho a la estabilidad en el empleo, pues le da continuidad a su relación de trabajo, y como consecuencia de ello provoca, a decir de Mario de la Cueva: "la reintegración en forma refleja de todos los derechos laborales del trabajador adquiridos en la fuente de trabajo con anterioridad al despido". ${ }^{8}$

Sin embargo, no en todos los casos en donde se demande la reinstalación en el puesto de trabajo y se demuestre la existencia de un despido injustificado, podrá obligarse al patrón a cumplir un laudo o sentencia cuya condena sea la reincorporación del trabajador en su fuente laboral, pues en casos de excepción, expresamente regulados en la Ley Federal del Trabajo, podrá válidamente eximirse al patrón a reinstalar al trabajador injustificadamente despedido, en cuyos supuestos la obligación de reinstalar podrá conmutarse por

8 Cueva, Mario de la, El nuevo derecho mexicano del trabajo. Historia, principios fundamentales, derecho individual y trabajos especiales, $15^{\text {a }}$ ed., México, Porrúa, 1998, t. I, p. 257. 
el pago de las indemnizaciones señaladas en el artículo 50 de la Ley Federal del Trabajo.

Por ello, la exención al patrón para reinstalar a un trabajador despedido injustificadamente, deriva del derecho de éste para solicitar de la autoridad jurisdiccional se le exima del restablecimiento del derecho a la estabilidad en el empleo, vulnerado en atención al despido injustificado, pero ello no lo libera de su obligación de reparación como se ha apuntado; por lo cual no debe entenderse a la obligación eximida como una excepción o flexibilización del derecho a la estabilidad en el empleo, pues como lo sostiene Luis María Aguilar Morales "el derecho a la estabilidad en el empleo se adquiere desde el momento mismo del inicio de la relación de trabajo" y todos los trabajadores gozan de dicho derecho.

\section{LIBERACIÓN DE LA OBLIGACIÓN DE REINSTALAR}

Una vez precisado lo anterior, y en atención al contenido del artículo 49 de la Ley Federal del Trabajo del cual se desprende el derecho patronal para solicitar se le exima de la obligación de reinstalar, veamos ahora cuáles son los elementos de este derecho, así como los supuestos de su procedencia cuando se haya emitido una condena para reincorporar al trabajador despedido. Debemos partir de la premisa normativa en comento, cuyo contenido reconoce la obligación ineludible del patrón para reparar el daño causado al trabajador por el despido injustificado, el cual es el hecho generador de la violación al derecho de la estabilidad en el empleo.

Si bien por virtud del derecho de permanencia en el puesto de trabajo el patrón no debe despedir sin justa causa a ninguno de sus trabajadores, los efectos de la violación a dicho mandato suelen ser diversos cuando se le demande la reincorporación de los operarios en sus puestos de trabajo, pues la obligación de reinstalarlos y restablecer sus relaciones laborales puede variar y ser flexible de conformidad a lo dispuesto en forma expresa o por exclusión por el artículo 49 de la Ley Federal del Trabajo; porción normativa en la cual se contiene el derecho patronal de ser eximido de reinstalar a sus trabajadores, así como la ineludible obligación de hacerlo.

El artículo 49 de la Ley Federal del Trabajo otorga al patrón el derecho de ser eximido de la obligación de reinstalar a los trabajadores despedidos, aten-

\footnotetext{
9 Aguilar Morales, Luis María, La relación y el contrato de trabajo, México, 2018, vol. 2, p. 45.
} 
diendo a dos criterios de procedencia para este derecho: el primero se refiere a una clasificación de trabajadores derivada de los servicios personales subordinados prestados en favor del patrón y el segundo atiende a la temporalidad de la duración de la relación de trabajo; por ello, de conformidad con dichos criterios de procedencia, debe entenderse al derecho de relevar la obligación en comento como una excepción a la regla general, la cual obliga al patrón de forma ineludible a reinstalar a sus trabajadores.

En cuanto al criterio de clasificación de trabajadores, las fracciones II, III, IV y V del artículo 49 de la Ley Federal del Trabajo disponen de forma correspondiente que al patrón podrá eximírsele de la obligación de reinstalar a los operarios despedidos injustificadamente cuando, por razón del trabajo que desempeñan los operarios o por las características de sus labores, están en contacto directo y permanente con el patrón, siendo por tanto imposible el desarrollo normal de la relación de trabajo, cuando se trate de trabajadores de confianza, trabajadores del hogar y trabajadores eventuales.

Respecto al segundo criterio de procedencia del derecho de exención a la reinstalación en estudio, la fracción I del artículo 49 de la ley laboral arriba citada autoriza a la patronal negarse a reincorporar a los operarios despedidos, con independencia de si la relación de trabajo se pactó por tiempo indeterminado, determinado, por obra determinada, para la inversión de capital determinado, por temporada o cualquiera otra, cuando la antigüedad de los trabajadores sea menor de un año, de ahí la circunstancia temporal como factor determinante en el derecho excepcional para eximir de la reinstalación en comento.

Ahora bien, el derecho patronal para liberarlo de la obligación a reinstalar a los trabajadores cuando, por razón del trabajo que éstos desempeñan o por las características de sus labores están en contacto directo y permanente con el patrón, se haga imposible el desarrollo normal de la relación de trabajo, debe considerarse pertinente, pues el contacto directo y permanente entre el patrón y el trabajador originariamente despedido y a la postre reinstalado atentaría contra la fuente de trabajo y generaría complicaciones futuras cuyo fin sería desastroso para ambas partes.

Resultaría ilógico por ejemplo, obligar a un patrón persona física a reinstalar a su chofer personal, despedido por haber sido sorprendido teniendo relaciones sexuales con la cónyuge del empleador, sin haber podido probar en juicio la falta de probidad y honradez, pues el restablecimiento de la relación laboral derivada de la reinstalación demandada pondría en riesgo inevitablemente el sano y normal desarrollo de la relación de trabajo; de 
ahí se advierte no sólo la coherencia del derecho otorgado al patrón para ser eximido a reinstalar, sino también la necesidad de otorgarle esa potestad a cambio del pago compensatorio correspondiente, materia de análisis en líneas más adelante.

Sin embargo, debemos plantear una problemática sobre el derecho de exención a la reinstalación respecto de los trabajadores en contacto directo y permanente con el patrón, pues aun cuando pudiera considerarse un tema de fácil comprensión, se torna complicado entender la procedencia de este derecho cuando el patrón es una persona jurídica, en atención a la complejidad para demostrar en ese supuesto el contacto directo y permanente entre el trabajador despedido y el patrón; es decir la persona jurídica, sin poder considerar a los socios, directores o administradores de ésta como patrones del trabajador con quienes no existe relación de trabajo.

En términos de lo dispuesto por el artículo 11 de la Ley Federal del Trabajo, los socios integrantes de una sociedad jurídica, sus directores, administradores y gerentes sólo son representantes del patrón, y en tal virtud "la persona moral será la única que esté sujeta al vínculo contractual", ${ }^{10}$ según lo ha sostenido el Sexto Tribunal Colegiado en Materia de Trabajo del Primer Circuito; por ello, en principio resulta inaplicable la hipótesis normativa en comento cuando el patrón sea una persona jurídica, así se trate del chofer de la empresa asignado al director general de la misma y se verifique el ejemplo arriba planteado.

Ante ello, resulta no sólo conveniente sino necesaria una reforma a la fracción II del artículo 49 de la Ley Federal del Trabajo, para adicionar el contacto directo y permanente entre el trabajador despedido y los representantes del patrón como causa de procedencia para el ejercicio del derecho patronal para ser eximido de reinstalar al operario, pues los efectos desfavorables en la relación de trabajo, de reinstalar a un trabajador cuyos servicios se presten en contacto directo y permanente con el patrón, resultan en la misma medida si dicho contacto se verifica entre aquél y los representantes de éste.

Por otra parte, la inclusión de los trabajadores del hogar en la fracción IV del artículo 49 de la legislación laboral en estudio, como una clasificación de aquéllos a quienes al patrón puede eximírsele de reinstalar, consideramos atiende a las mismas razones lógicas señaladas para la fracción II de dicho precepto, pues el contacto directo y permanente existente entre estos traba-

10 Tesis I.6o.T. J/98, Semanario Judicial de la Federación y su Gaceta, novena época, t. XXX, septiembre de 2009, p. 2993. 
jadores y el patrón es el factor determinante para conceder al empleador el derecho para relevar su obligación de reincorporarlos en la fuente de trabajo, dado los efectos desfavorables presentes en la reanudación de la relación laboral después de una reinstalación forzada.

El derecho de exención en comento, respecto de los trabajadores de confianza, se debe advertir de la necesidad de conceder a la patronal la posibilidad de no reinstalar a dichos trabajadores después de un despido injustificado, en atención a las facultades de mando específicas reconocidas a dichos operarios; es decir, las funciones de dirección, inspección, vigilancia y fiscalización. De ello se desprende la calidad de representantes del patrón a los trabajadores de confianza, de ahí el derecho patronal de ser eximido de reinstalarlos en atención a la representación, situación generadora de los mismos efectos desfavorables citados.

En ese orden de ideas, la pertinencia de incluir a los trabajadores eventuales en la lista de la clasificación de operarios a quienes al patrón puede válidamente eximirse de su reinstalación, en términos de lo dispuesto en la fracción V del artículo 49 de la Ley Federal del Trabajo, obedece a criterio nuestro a la falta de necesidad permanente de los trabajadores eventuales; por tanto, el derecho de exención a la reincorporación no atiende a los mismos criterios de los trabajadores antes señalados, sino a la pertinencia de utilidad de esta clasificación de trabajadores, sin que sea objeto de nuestro estudio profundizar sobre trabajadores eventuales.

Ahora bien, por cuanto hace al criterio de temporalidad de los trabajadores despedidos cuya búsqueda sea la reinstalación en su fuente de trabajo, sin atender a clasificación alguna de operarios como en los supuestos antes señalados, la fracción I del artículo 49 de la legislación laboral en estudio, autoriza al patrón a no cumplir la condena de reinstalar a los trabajadores cuya antigüedad en la fuente de trabajo sea menor de un año; sin dar lugar a interpretación a contrario sensu de forma indiscriminada, pues la patronal no se verá obligada a reinstalar a todos los trabajadores con antigüedad de un año o más, como lo hemos visto anteriormente.

Coincidimos con el ministro Luis María Aguilar Morales, quien señala: "La idea fundamental de la estabilidad en el empleo es que el trabajador lo conserve mientras se cumplan tres condiciones básicas: a) que la actividad que desempeña sea necesaria para el patrón, b) que conserve la capacidad para desarrollarla, y c) que no incurra en causa que justifique el despido". ${ }^{11}$

11 Aguilar Morales, Luis María, op. cit., p. 100. 
Por tanto, consideramos injustificado el criterio de temporalidad para autorizar al empleador a no reinstalar a los trabajadores despedidos injustificadamente, pues el derecho al restablecimiento de la estabilidad en el empleo no debe sujetarse a la antigüedad de los trabajadores en la fuente de trabajo, pues el derecho a la estabilidad en cita se adquiere, como hemos dicho, en el momento del nacimiento de la relación de trabajo, y la violación a esa prerrogativa es igual de grave respecto de un trabajador con menor o mayor antigüedad de un año; en consecuencia, el tiempo no debe ser factor para afectar su restablecimiento.

\section{LOS PAGOS COMPENSATORIOS}

DE LA OBLIGACIÓN DE REINSTALAR

La exención al patrón de la obligación de reinstalar a los trabajadores despedidos de manera injustificada no debe considerarse una cuestión de impunidad ante la eventual condena a ello, emitida por la Junta de Conciliación y Arbitraje o por los tribunales laborales, pues como lo hemos señalado, la procedencia de eximirlo está sujeta a la verificación de los supuestos ya analizados en líneas que anteceden, así como del pago sustitutivo al restablecimiento del derecho violado, de las indemnizaciones en los términos señaladas en el artículo 50 de la Ley Federal del Trabajo, cuyos matices son variables como veremos en líneas siguientes.

Cabe citar a Eduardo Giorlandini y a Rodolfo Capón Filas, quienes sostienen: "La indemnización es la reparación de la ilicitud de la conducta del agente" 12 ; es decir, toda indemnización tiene un carácter reparador de una falta cuantificable en dinero cuyo monto en el derecho del trabajo está determinado en la Ley Federal del Trabajo. Sin embargo, el pago de las indemnizaciones que sustituyen al restablecimiento del derecho a la estabilidad en el empleo no tiene su génesis en el hecho ilícito del despido injustificado, sino en el ejercicio del derecho patronal de relevarle la reinstalación condenada.

Aun cuando los efectos producidos por las indemnizaciones sustitutivas de la obligación de reinstalar a los operarios son los mismos generados por la indemnización resarcitoria del despido injustificado, pues ambas concluyen

12 Capón Filas, Rodolfo y Giorlandini, Eduardo, Diccionario de derecho social. Derecho del trabajo y la seguridad social. Relación individual del trabajo, México, UNAM/Instituto de Investigaciones Jurídicas, 2016, p. 283; disponible en https://biblio.juridicas.unam.mx/bjv/, consultado el 11 de noviembre de 2018. 
de forma definitiva la relación de trabajo, coincidimos con Mario de la Cueva quien sostiene: "no se debe confundir dicha indemnización generada como causa del despido alegado, con la que debe pagar el patrón como consecuencia de su negativa a reinstalar al trabajador en su puesto de trabajo en cumplimiento a la condena establecida por la autoridad competente"13.

Si bien la Ley Federal del Trabajo denomina "indemnizaciones" a los pagos sustitutivos de la obligación patronal de reinstalar a los trabajadores despedidos, debemos entender la naturaleza jurídica de los mismos, la cual lejos de ser resarcitoria de una conducta ilícita, es conmutativa y por tanto compensatoria de la falta de obligatoriedad patronal de reinstalar a los operarios. Por esto los pagos en comento no son reparadores en sí mismos del despido injustificado, sino conmutan una prestación por otra, de ahí lo inexacto de su denotación legal; esto es, no deben considerarse indemnizaciones sino pagos compensatorios.

De conformidad con el artículo 50 de la ley laboral en estudio, el monto de los pagos compensatorios - indemnizaciones para la Ley Federal del Trabajo- sustitutivos de la obligación patronal de reinstalar a los trabajadores despedidos, tiene matices diferentes que dependen de criterios de temporalidad de la relación de trabajo, sin importar la clasificación de trabajadores expuesta con antelación; es decir, para calcular el monto de dichos pagos únicamente se atiende a la duración del vínculo laboral pactada en el contrato de trabajo o a la regulación legal, lo cual constituye el elemento fundamental para diferenciar el cálculo de los pagos compensatorios.

Las fracciones I y II del artículo 50 de la Ley Federal del Trabajo establecen criterios de temporalidad para determinar el cálculo diferenciado de los pagos compensatorios sujetos a nuestro análisis, señalando tres criterios de cuantificación: el primero se refiere a las relaciones de trabajo pactadas por tiempo determinado menor a un año, el segundo hace referencia a las relaciones laborales igualmente acordadas por tiempo determinado, pero con una duración mayor de un año; por su parte, el tercer criterio se ocupa de las relaciones de trabajo pactadas por tiempo indeterminado.

En ese orden de ideas, la porción normativa en cita establece la obligación patronal de pagar el importe de los salarios correspondientes a la mitad del tiempo de duración efectiva de la relación de trabajo, si ésta fuere pactada por tiempo determinado menor a un año, o bien el importe de los salarios de 6 meses por el primer año efectivo de trabajo más 20 días por cada año

13 Cueva, Mario de la, op. cit., p. 69. 
subsecuente, si la relación fuere por tiempo determinado mayor a un año, así como de pagar los salarios correspondientes a 20 días por cada año de trabajo si el vínculo fuere por tiempo indeterminado.

Un primer planteamiento crítico respecto de los criterios de temporalidad para el cálculo diferenciado de los pagos compensatorios en comento, atiende a la omisión del legislador por cuanto hace a las relaciones de trabajo por tiempo determinado de un año, pues el precepto legal en estudio sólo se refiere a las relaciones de trabajo por tiempo determinado, menores y mayores de una anualidad; sin embargo, es evidente la solución a la omisión legislativa, pues el monto del pago deberá calcularse como si se tratare de relaciones de trabajo por tiempo determinado menor de un año, pues no resultaría lógico resolver dicha omisión en otro sentido.

A manera de recordatorio, nos parece pertinente puntualizar lo siguiente: para la procedencia de eximir al patrón a reinstalar, así como para el cálculo diferenciado de los pagos compensatorios, siempre será necesaria la concurrencia de al menos una hipótesis normativa del artículo 49 de la Ley Federal del Trabajo, pues ya sea que se trate de relaciones de trabajo por tiempo determinado o por tiempo indeterminado, siempre deberá combinarse dicha duración con al menos una de las clasificaciones de trabajadores referida en el precepto legal en cita o con el criterio de temporalidad establecida en la fracción I de dicho artículo.

Por cuanto hace al criterio de temporalidad establecido en el artículo 49 de la ley laboral en estudio, en una primera hipótesis tenemos: en cualquier caso el patrón podrá negarse a reinstalar a trabajadores con antigüedad menor a un año en la fuente de trabajo, sin importar su categoría o la forma de realizar sus funciones o servicios prestados; para determinar el criterio aplicable al cálculo del pago compensatorio de dichos trabajadores, se debe atender al pacto celebrado para la duración de la relación de trabajo — tiempo determinado menor o mayor de un año o por tiempo indeterminado- y no al tiempo efectivo de la prestación de los servicios; así en esta hipótesis podríamos tener las variables que a continuación describiremos.

Si la relación de trabajo fue pactada por tiempo determinado menor a un año, la antigüedad del trabajador en la fuente de trabajo necesariamente también será menor a una anualidad; por tanto, el pago compensatorio, materia de nuestro estudio, se debe calcular de acuerdo al importe de los salarios correspondientes a la mitad del tiempo de los servicios prestados; es decir, si la antigüedad del trabajador fue de dos meses, el pago será de un mes, si la antigüedad fue de once meses, el pago lo será de cinco meses 
y medio. Así se conjugan los elementos de los artículos 49 y 50 de la Ley Federal del Trabajo.

En una segunda hipótesis, podríamos observar una relación de trabajo por tiempo determinado pactada, por un tiempo mayor de un año, en donde las variables, a pesar de la duración pactada, podrían verificarse en la forma siguiente: si la antigüedad del trabajador fuera sólo de dos meses, el pago compensatorio será calculado en forma proporcional a los seis meses correspondientes al primer año; de tal forma corresponderá también al importe de un mes de salario. En cambio, si la antigüedad fuera de un año y medio, el pago corresponderá al importe de 6 meses de salario por el primer año y la proporción del segundo año sobre la base de 20 días anuales.

De las dos hipótesis anteriores observamos un equilibrio en el pago compensatorio, materia de nuestro análisis, respecto de la antigüedad menor de un año de los trabajadores contratados por tiempo determinado, con independencia de si el límite es menor o mayor de una anualidad; es decir, la proporción económica en ambos casos es la misma; por tal motivo consideramos innecesaria la distinción normativa referente al periodo por el cual se pacte el tiempo determinado, pues ello constituye una sobrerregulación normativa capaz de crear confusiones en los actores principales de la relación laboral: esto es, trabajadores y patrones.

Sin embargo, una tercera hipótesis nos permite visualizar una desproporción normativa respecto de trabajadores con una antigüedad menor de un año en la fuente de trabajo, pero contratados en una relación laboral por tiempo indeterminado, pues la fracción II del artículo 50 de la Ley Federal del Trabajo, como lo hemos dicho, ordena calcular el pago compensatorio derivado del relevo a su reinstalación sobre la base de 20 días de salario por cada año de trabajo. Ello les genera una desventaja grave, contraria a los principios de justicia y de igualdad en el derecho del trabajo.

De esta manera, si al patrón se le exime de reinstalar a un trabajador, luego de un despido injustificado con una antigüedad de dos meses — como en las hipótesis anteriores - pero contratado en una relación de trabajo por tiempo indeterminado, el pago compensatorio debe calcularse en proporción al importe de los salarios de 20 días por cada año de trabajo; es decir, en el supuesto planteado, el trabajador sólo tendrá derecho al pago compensatorio del importe de 3.33 días de salario, frente al pago de un mes de salario correspondiente a un trabajador con la misma antigüedad, pero contratado por tiempo determinado.

Lo anterior es inaceptable en atención al espíritu social del derecho del trabajo, máxime si se observa el crecimiento de la desproporción con el trans- 
curso del tiempo, pues se debe advertir el pago compensatorio correspondiente a 6 meses de salario a un trabajador con una antigüedad de un año contratado por tiempo determinado, en oposición al pago de 20 días de salario correspondiente a los trabajadores con la misma antigüedad, pero contratados por tiempo indeterminado. Las hipótesis anteriores nos dejan ver la irrisoria conveniencia de una contratación por tiempo determinado sobre la de una por tiempo indefinido.

Por esto, más allá de la necesidad de una reforma a la Ley Federal del Trabajo, ante los supuestos de hecho y porciones normativas comentadas se pone sin duda a prueba la habilidad jurídica de postulantes y autoridades jurisdiccionales del trabajo para buscar los medios por los cuales se logre un equilibrio en los derechos de los trabajadores, a la luz, por ejemplo del principio pro personae, ello con la finalidad de superar la deficiencia legislativa generadora de desigualdad en las prerrogativas de la clase obrera y contraria no sólo a los fines del derecho del trabajo mexicano, sino también del derecho internacional del trabajo.

En otro orden de ideas y en cuanto al cálculo de los pagos compensatorios en estudio, respecto de la clasificación de trabajadores arriba señalada, éste deberá realizarse atendiendo a los mismos criterios planteados en el artículo 50 de la Ley Federal del Trabajo; es decir, se deberá tomar en cuenta si la contratación fue por tiempo determinado menor o mayor de un año o bien por tiempo indeterminado, en combinación de la antigüedad del operario. La diferencia relevante atañe a la posibilidad de eximir al patrón de la obligación de reinstalar a dichos trabajadores, aun cuando tengan una antigüedad mayor de un año.

El artículo 50 de la Ley Federal del Trabajo, también otorga a los trabajadores el derecho a recibir del patrón además de los pagos compensatorios arriba descritos, el pago de una "indemnización" correspondiente a tres meses de salario aunado a los salarios vencidos. No debemos identificar el pago de estos tres meses con la indemnización regulada en el apartado A del artículo 123 constitucional ni con la señalada en el artículo 48 de la Ley Federal del Trabajo, pues el pago señalado en el artículo 50 comparte la misma naturaleza compensatoria de los demás pagos estudiados, pues su origen no es en sí mismo el despido injustificado.

Cuestión diversa ocurre con el pago de salarios vencidos, pues el propio artículo 50 de la legislación laboral en estudio hace referencia a los términos establecidos en el diverso artículo 48; esto es, todo trabajador despedido sin importar el tipo de pretensión que haya exigido de su patrón (indemnización 
o reinstalación) tendrá derecho al pago de salarios vencidos e intereses. Sin ser materia de nuestro análisis, consideramos pertinente precisar la naturaleza indemnizatoria de los salarios vencidos, pues aun cuando se paguen como consecuencia de la exención, éstos proceden también frente a una reinstalación obligada.

\section{LA REINSTALACIÓN OBLIGATORIA}

Como lo hemos explicado con antelación, el derecho del patrón para ser eximido de la obligación de reinstalar a los operarios despedidos de forma injustificada es excepcional y sólo procede en los casos ya planteados en el presente artículo, pues la regla general obliga al patrón a restablecer el derecho a la estabilidad en el empleo de los trabajadores cuando así lo hayan demandado, por tanto la reinstalación será obligatoria sin dar oportunidad a la parte patronal a no cumplir el laudo o la sentencia mediante la cual se le condene reincorporar a sus trabajadores. Desde un punto de vista teórico, en estos casos el cumplimiento a reinstalar es ineludible, pudiéndose lograr incluso mediante la ejecución forzosa del laudo o de la sentencia.

Sin embargo, la experiencia fáctica nos ha permitido observar diversas problemáticas, en algunos casos graves, generadas en gran medida por la propia norma jurídica, creando en muchas de las veces escenarios muy desfavorables para los trabajadores, luego de seguir juicios largos y desgastantes, en donde a pesar de obtener laudos condenatorios al patrón para reinstalarlos en sus puestos de trabajo, no ven jamás materializado el restablecimiento de su derecho a la estabilidad en el empleo, en atención a la oposición patronal al cumplimiento de la condena, la cual si bien no es de derecho sí se presenta de hecho.

Si bien desde una óptica teórica es posible obligar al patrón a reinstalar a sus trabajadores mediante una ejecución forzada del laudo o de la sentencia, debemos cuestionarnos hasta dónde realmente es eficaz una norma cuyo contenido pretende proteger a la clase trabajadora, pero con efectos de hecho probablemente más devastadores a la violación del derecho en sí. Si bien la rescisión de las relaciones laborales no debe estar sujeta al capricho del patrón, buscar la reinstalación en muchos casos no es la solución más conveniente fácticamente para los trabajadores.

La reinstalación obligatoria implica en primer lugar devolver a los trabajadores a una fuente de trabajo en la cual originariamente ya no eran bienve- 
nidos, por lo tanto, en la mayoría de los casos es reintegrarlos a un ambiente laboral hostil cuya tensión comienza en la diligencia misma de la reinstalación, pues además de los motivos propios generadores del despido, la prosecución de un juicio en el cual el patrón resultó vencido provoca rencores y situaciones negativas en las relaciones laborales forzadas a reanudarse por una decisión jurisdiccional; esto es, ningún trabajador es recibido con bombos y platillos después de la reinstalación forzada.

La experiencia nos ha enseñado como una de las primeras consecuencias de una reinstalación obligatoria, la generación en muchos casos de nuevos despidos, instantes siguientes a la reinstalación; o bien, en ocasiones no tan favorables para el trabajador, hemos vistos innumerables acontecimientos lamentables, en los cuales el patrón mal aconsejado fabrica delitos a los operarios reinstalados para después conseguir de ellos una renuncia a su puesto de trabajo a cambio de liberarlo del conflicto penal maliciosamente maquilado. En estos supuestos, la reinstalación obligatoria representa para los trabajadores un gran fracaso.

En el sector privado, la reinstalación obligatoria, lejos de ser una forma de protección a la clase trabajadora, se ha convertido de forma recurrente en una oportunidad patronal para tomar revancha de un juicio perdido; luego, la reincorporación forzada sólo presenta beneficios para trabajadores sindicalizados afiliados a una organización sindical realmente activa en la defensa de sus derechos. Si bien el estudio del derecho colectivo de trabajo no es materia de nuestro presente trabajo, resulta pertinente cuestionar cuántas organizaciones sindicales realmente llevan a cabo dicha función; lamentablemente no son muchas.

En la mayoría de los conflictos de trabajo consideramos inconveniente la reinstalación obligatoria o forzada, porque en muchos de ellos su génesis viene de despidos completamente justificados fácticamente, pero injustificados a los ojos de la justicia del derecho del trabajo, por no haber podido probar en juicio su causa justificada debido a cuestiones meramente del procedimiento; luego la reinstalación pone fin al conflicto jurisdiccionalmente planteado por las partes, pero de ninguna manera resuelve el conflicto originariamente generado entre patrón y trabajador en la relación de trabajo.

La regla general de la reinstalación obligatoria o forzada, por la cual se impide al patrón ser eximido de reincorporar a sus trabajadores injustificadamente despedidos, es altamente motivadora como discurso social en la protección de los derechos de los trabajadores, — particularmente el de la estabilidad en el empleo- - pero debemos reconocer con ojos objetivos el alcance 
ineficaz de la norma jurídica frente al mundo de los hechos, pues en las más de las veces lejos de brindar protección a la clase trabajadora, la coloca en un nuevo estado de indefensión a merced de la clase patronal y no hace más sino prolongar sus conflictos en sus relaciones de trabajo.

Sin pretender vulnerar los derechos de los trabajadores, consideramos necesario, ante la problemática planteada, analizar de manera más profunda el derecho del patrón para ser eximido de la obligación de reinstalar a los trabajadores ante una eventual condena a ello, pues debemos apreciar a la reinstalación no sólo como un mero acto jurídico de restablecimiento al derecho de estabilidad en el empleo, sino que es necesario observar sus alcances a la luz de una relación laboral forzada, sopesando de manera crítica si con la reinstalación obligatoria se materializa el cumplimiento de los fines del derecho del trabajo.

Si bien tenemos claro el objeto de la reinstalación obligatoria como precursora de la continuidad en las relaciones de trabajo para la generación de mejores derechos de los trabajadores, tales como derechos de antigüedad, ascenso y escalafón, más vacaciones, mejores expectativas en materia de seguridad social, entre otros; también es evidente la ineficacia del objeto ante la falta de una relación laboral sana, seguida de una reinstalación obligatoria, pues la reincorporación de los operarios no resuelve de forma alguna el conflicto de trabajo motivo del despido, lo cual sería indispensable en una continuidad forzada de la relación laboral entre las partes.

Ante el reclamo de un despido injustificado, la pretensión de una indemnización o de una reinstalación presenta problemáticas diversas, pues mientras en la primera sólo se debe resolver si la separación del operario fue justificada o injustificada, el planteamiento de la reinstalación debe suponer además el estudio de la viabilidad de la continuidad de la relación de trabajo como limitadamente lo establece el artículo 49 de la Ley Federal del Trabajo; sin embargo, no debe presumirse sin más la conveniencia de la continuidad citada en los casos no previstos en dicha porción normativa.

Con el objeto de lograr una verdadera protección a la clase trabajadora, nosotros proponemos invertir los alcances de la porción normativa reguladora del derecho patronal para eximírsele de la obligación de reinstalar a los trabajadores despedidos; esto es, consideramos pertinente hacer del derecho a ser eximido de reincorporar a los trabajadores la regla general, y considerar como excepción al derecho en comento, los supuestos en los cuales la obligatoriedad patronal para reinstalar a los trabajadores sea ineludible, forzándole a restablecer el derecho a la estabilidad en el empleo cuando así le sea demandado. 
En un primer análisis proponemos como supuestos de excepción para la improcedencia del relevo de la obligatoriedad de la reinstalación forzada, aquellos supuestos de despidos de trabajadores sindicalizados en donde la reinstalación de los agremiados a las organizaciones sindicales no sólo tiene efectos en las relaciones individuales de trabajo, sino también en la relación colectiva entre el patrón y el sindicato correspondiente, pues en los despidos de trabajadores sindicalizados la falta de reinstalación obligatoria podría afectar el interés profesional de la clase trabajadora.

\section{PROCEDIMIENTO PARA EXIMIR AL PATRÓN}

\section{DE LA OBLIGACIÓN DE REINSTALAR}

El procedimiento para eximir al patrón de la obligación de reinstalar a los trabajadores despedidos, durante mucho tiempo ha sido un tema de grandes confusiones tanto en la doctrina, en las Juntas de Conciliación y Arbitraje, como en las interpretaciones jurisprudenciales de nuestros más altos tribunales; y seguramente para nuestro criterio, y en atención al contenido de nuestra Ley Federal del Trabajo, la confusión citada continuará prevaleciendo en los nuevos juzgados laborales. Por tanto, consideramos pertinente realizar un análisis respecto de la forma por la cual se ha llevado a cabo el procedimiento para eximir al patrón de reinstalar a los operarios.

Anterior a las reformas a la Ley Federal del Trabajo, publicadas el $1^{\circ}$ de mayo de 2019, el patrón era eximido de reinstalar a los trabajadores mediante uno de dos procedimientos a elegir por el patrón, regulados en la legislación en comento: la insumisión al arbitraje o el no acatamiento del laudo; sin embargo, en la práctica algunos patrones después de un ejercicio de interpretación obtenían la exención de reinstalar mediante un procedimiento paraprocesal. A partir de la reforma citada, se otorga a los patrones la opción, ahora sí expresamente señalada, para obtener dicha exención mediante el procedimiento paraprocesal regulado en el diverso artículo 982.

Por ello, el objeto de nuestro estudio se debe centrar en los tres procedimientos arriba señalados por medio de los cuales se ha eximido al patrón de la obligación de reinstalar a los trabajadores despedidos, con el fin de desentrañar la confusión en los procedimientos, sostenida en párrafos anteriores, presentando incluso a nuestro lector las inconveniencias jurídicas de llevarlos a cabo, y proponiendo según nuestro entendimiento la forma procesal correcta para obtener la exención en comento. Para lo cual, consideramos necesario 
realizar un breve recuento histórico constitucional a partir de nuestra carta magna de 1917.

La redacción original de la fracción XXI del artículo 123 constitucional en 1917 disponía:

XXI. Si el patrono se negare a someter sus diferencias o al arbitraje o a aceptar el laudo pronunciado por la Junta, se dará por terminado el contrato de trabajo y quedará obligado a indemnizar al obrero con el importe de tres meses de salario, además de la responsabilidad que le resulte del conflicto. Si la negativa fuera de los trabajadores se dará por terminado el contrato de trabajo. ${ }^{14}$

Del texto constitucional transcrito podemos observar el nacimiento de las figuras jurídicas de la insumisión al arbitraje y no acatamiento del laudo, reguladas posteriormente en la Ley Federal del Trabajo; porción constitucional normativa cuyo contenido se mantuvo vigente hasta el 21 de noviembre de 1962, pues a partir del 22 del mismo mes y año entró en vigor la reforma constitucional al artículo 123 en la cual fue modificada la fracción en comento, así como la diversa fracción XXII cuyo interés para nuestro estudio cobra fuerza desde la citada reforma. Después de dicha fecha, las fracciones en comento dispusieron:

XXI. Si el patrono se negare a someter sus diferencias o al arbitraje o a aceptar el laudo pronunciado por la Junta, se dará por terminado el contrato de trabajo y quedará obligado a indemnizar al obrero con el importe de tres meses de salario, además de la responsabilidad que le resulte del conflicto. Esta disposición no será aplicable en los casos de las acciones consignadas en la fracción siguiente. Si la negativa fuera de los trabajadores se dará por terminado el contrato de trabajo.

XXII. "(sic) El patrono que despida a un obrero sin causa justificada o por haber ingresado a una asociación o sindicato o por haber tomado parte en una huelga lícita, estará obligado a elección del trabajador a cumplir el contrato o a indemnizarlo con el importe de tres meses de salario. La ley determinará los casos en que el patrono podrá ser eximido de la obligación

14 Suprema Corte de Justicia de la Nación, Constitución Política de los Estados Unidos Mexicanos, texto original, México, 5 de febrero de 1917, p. 159; disponible en bttps:/ www.scjn. gob.mx/sites/default/files/pagina-micrositios/documentos/2016-12/00130029.pdf, consultado el 8 de enero de 2021. 
de cumplir el contrato, mediante el pago de una indemnización. Igualmente tendrá la obligación de indemnizar al trabajador con el importe de tres meses de salario, cuando se retire del servicio por falta de probidad del patrono o por recibir de él malos tratamientos, ya sea en su persona o en la de su cónyuge, padres, hijos o hermanos. El patrón no podrá eximirse de esta responsabilidad cuando los malos tratamientos provengan de dependientes o familiares que obren con el consentimiento o tolerancia de él" (sic). ${ }^{15}$

Como puede observarse, con esta reforma, por un lado, se introduce restricción constitucional en la fracción XXI comentada al derecho de los patrones a la insumisión al arbitraje y al no acatamiento del laudo, y por otro, en la fracción XXII del mismo artículo se crea el derecho patronal para ser eximido de la obligación de cumplir el contrato de trabajo cuando los trabajadores despedidos de forma injustificada le demanden la reinstalación en su puesto de trabajo. Cuestiones relevantes para nuestro estudio, si consideramos el sistema jurídico de supremacía constitucional, el cual sólo mencionamos sin ser objeto de nuestro análisis.

Como referencia histórica debemos señalar la última reforma constitucional al apartado A del artículo 123 de fecha 24 de febrero de 2017, en la cual, respecto al interés de nuestro presente trabajo académico, debemos mencionar la modificación realizada a la fracción XXI, en donde esencialmente se sustituye la frase: "aceptar el laudo pronunciado por la Junta" por: "cumplir con la resolución", quedando la redacción vigente de esta la fecha tanto de la fracción citada como de la antes señalada fracción XXII, la cual no fue modificada en la reforma citada en el presente párrafo.

Por tanto, la insumisión al arbitraje todavía previsto en la Constitución (cuyo tema resulta apasionante, dejando su análisis para otro momento), así como el no acatamiento de la resolución, no proceden en los casos en los cuales se demande al patrón la indemnización o la reinstalación derivadas de un despido injustificado, según disponen las fracciones XXI y XXII del apartado A del artículo 123 constitucional; es decir, en dichos supuestos le debe ser imposible al patrón negarse a someter sus diferencias al "arbitraje" o negarse a cumplir con la resolución, pues ello sólo procede cuando se trate de acciones diversas a las señaladas.

15 Suprema Corte de Justicia de la Nación, Decreto que reforma el artículo 123 de la Constitución Política de los Estados Unidos Mexicanos, México, 21 de noviembre de 1962, p. 2; disponible en bttps:// www.scjn.gob.mx/sites/default/files/cpeum/decretos_reformas/2016-12/00130081. $p d f$, consultado el 8 de enero de 2021. 
Somos concordantes con lo sostenido por el Primer Tribunal Colegiado en Materia de Trabajo del primer circuito al señalar:

Si el trabajador en su escrito de demanda afirma que se le despidió, el patrón está impedido legalmente para negarse a someter al arbitraje, en términos del artículo 947 de la Ley Federal del Trabajo, porque tal facultad, tratándose del despido, la reprime el artículo 123, apartado "A", fracciones XXI y XXII, de la Constitución Política de los Estados Unidos Mexicanos. ${ }^{16}$

Sin embargo, resulta pertinente mencionar lo sostenido por la Segunda Sala de la Suprema Corte de Justicia de la Nación, quien sostiene:

...la regla general es que en la acción de reinstalación derivada de un despido injustificado es improcedente tanto la insumisión al arbitraje como la negativa a acatar el laudo por la parte patronal. Sin embargo, la fracción XXII del citado apartado prevé que la ley determinará los casos en que el patrón podrá ser eximido de la obligación de cumplir el contrato mediante el pago de una indemnización, lo que significa que deja a la ley ordinaria la reglamentación de las excepciones a dicha regla, que de acuerdo con el artículo 49 de la Ley Federal del Trabajo. ${ }^{17}$

No podemos dejar de manifestar nuestro total desacuerdo con lo sostenido por la Segunda Sala de la Suprema Corte de Justicia de la Nación, en tanto consideramos desafortunada la interpretación realizada a la fracción XXII del apartado A del artículo 123 constitucional, pues a nuestro criterio el máximo Tribunal confunde el derecho patronal de la insumisión al arbitraje y el no acatamiento de la resolución con la diversa prerrogativa para eximir al patrón de reinstalar a los trabajadores despedidos, señalados en el artículo 49 de la Ley Federal del Trabajo, ubicando de manera equívoca a esta prerrogativa como excepción de la regla general señalada.

Por un lado, la insumisión al arbitraje o el no acatamiento de la resolución deben entenderse como derechos procesales del patrón, pues atienden a cuestiones estrictamente del proceso; el primero para no someterse a la prosecución del juicio ante la Junta o el Tribunal del Trabajo, y el segundo para no

16 Tesis I.1o.T.24 L, Semanario Judicial de la Federación y su Gaceta, novena época, t. II, diciembre de 1995, página 491.

17 Tesis 2a./J. 163/2006, Semanario Judicial de la Federación y su Gaceta, novena época, t. XXIV, diciembre de 2006, p. 198. 
aceptar la resolución emitida en el mismo. Por otro lado, el derecho del patrón para ser eximido de la obligación de cumplir el contrato de trabajo tiene una naturaleza sustantiva, pues permite a la patronal el relevo de una prestación consignada en un laudo o sentencia por otra, con la anuencia de la autoridad jurisdiccional correspondiente.

Resulta entonces inexacto considerar al derecho patronal para ser eximido de cumplir con el contrato de trabajo en los supuestos contenidos en el artículo 49 de la Ley Federal del Trabajo, como excepciones a la improcedencia de la insumisión al arbitraje o al no acatamiento de la resolución cuando se trate de la pretensión de reinstalación derivada de un despido injustificado, pues eximir a los empleadores de reinstalar no implica por supuesto ni la insumisión al juicio ni el no acatamiento de la resolución; por el contrario, la liberación de la reincorporación a cambio de pagos compensatorios deviene de un acto de autoridad y no de una negativa patronal.

A mayor abundamiento, el último párrafo del artículo 947 de la Ley Federal del Trabajo establece la improcedencia del derecho patronal a la insumisión al arbitraje y el no acatamiento de la resolución en los casos en los cuales se demanden pretensiones derivadas de un despido injustificado; ello confirma nuestra hipótesis para diferenciar el derecho de oposición patronal a someterse al juicio o la resolución en él pronunciada, del derecho para ser eximido de cumplir el contrato de trabajo y con ello restablecer el derecho de la estabilidad en el empleo de los trabajadores despedidos. Sin dar lugar a considerar al derecho de exención como excepción a la improcedencia de la insumisión o no acatamiento.

Procesalmente hablando, resulta incompatible eximir al patrón de la obligación de cumplir con el contrato de trabajo de los trabajadores despedidos injustificadamente, cuya acción sea la reinstalación en su puesto de trabajo, cuando la solicitud de dicha exención sea planteada por medio de un incidente de insumisión al arbitraje o de no acatamiento de laudo — aun cuando este último se plantee como excepción-, pues dichos incidentes deben ser inadmisibles por improcedentes; luego entonces la resolución a dicho incidente en la cual se exima al patrón o se declare procedente la excepción de no acatamiento de la resolución entraña una inconstitucionalidad.

En otro orden de ideas, consideramos procedente, tanto antes de las reformas a la Ley Federal del Trabajo de 2019 como posterior a ellas, solicitar se exima al patrón de la obligación de restablecer el derecho de permanencia en la fuente de trabajo de los trabajadores despedidos, mediante un procedimiento paraprocesal; sin embargo, a nuestro criterio resulta no 
sólo inconveniente sino incluso a veces devastador para el patrón promover este tipo de procedimientos, pues indefectiblemente entrañan la confesión de la patronal de un despido injustificado, afectando sus defensas ante un eventual juicio futuro.

El supuesto jurídico de nuestro interés por el cual procede un procedimiento paraprocesal se refiere a la ausencia de conflicto entre las partes; por lo tanto, la prosecución de uno de estos procedimientos para lograr que se exima al patrón de la obligación de reinstalar, importa la ausencia de debate respecto no sólo de la existencia de un despido, sino también de la falta de justificación del mismo, luego entonces los conflictos posibles de generarse ante ello sólo atenderían a la verificación de los supuestos del artículo 49 de la Ley Federal del Trabajo o al monto de los pagos compensatorios consignados por el patrón.

En la práctica jurídica hemos tenido la desafortunada oportunidad de encontrarnos con múltiples eventualidades en donde el patrón termina pagando grandes cantidades económicas a los trabajadores despedidos, después de incoar los procedimientos paraprocesales para solicitar se le exima de la obligación de cumplir el contrato de trabajo, pues ello da oportunidades procesales a los abogados de trabajadores para iniciar por su parte juicios por despidos injustificados con innumerables ventajas generadas a partir de las confesiones expresas realizadas por los patrones, modificando hechos en su beneficio.

Aun cuando ahora el artículo 49 de la Ley Federal del Trabajo faculta expresamente a la patronal iniciar los procedimientos paraprocesales en comento, pensamos que se debe ser muy cuidadoso al decidir incoarlos y reconocer con ello despidos injustificados, para evitar consecuencias desfavorables en el futuro; para comprender mejor nuestra advertencia pongamos en la mesa un ejemplo en donde los efectos de buscar la liberación de reinstalar mediante un procedimiento paraprocesal resultarían desfavorables para el patrón y lo perjudicaría por la eventualidad de un juicio futuro por despido injustificado.

Recordemos nuestra hipótesis planteada anteriormente en donde un trabajador contratado por tiempo indeterminado es despedido al cumplir su segundo mes de trabajo; si el patrón reconoce lo injustificado de la separación y solicita mediante un procedimiento paraprocesal se le exima de la obligación de cumplir el contrato de trabajo por tratarse de un trabajador con una antigüedad menor de un año, estaría obligado a exhibir el pago compensatorio por el importe de 3.33 días de salario como lo vimos anteriormente, en términos de la fracción II del artículo 50 de la Ley Federal del Trabajo; más el pago de tres meses de salario y los vencidos, en su caso. 
Sin embargo, al notificarse y dar vista al trabajador con el procedimiento paraprocesal correspondiente, bien podría el operario iniciar por cuenta separada un juicio ordinario en el cual se queje de un despido injustificado (ya confesado por el patrón) y demandar el pago de la indemnización constitucional señalada en líneas anteriores, sin pretender reinstalación alguna y en consecuencia no dar lugar a la insumisión al arbitraje ni al no acatamiento de la resolución, debiéndose sustanciar un juicio con resultados inminentemente desfavorables al patrón, quien deberá pagar un monto mayor de salarios vencidos e intereses.

Del ejemplo anterior podemos observar la inconveniencia planteada para solicitar se exima al patrón de la obligación de cumplir con el contrato de trabajo, mediante el procedimiento paraprocesal, como lo refiere el artículo 49 de la Ley Federal del Trabajo, pues el patrón puede quedar sin defensa en un juicio cuya pretensión no sea la reinstalación del operario en su puesto de trabajo, pues al confesar el despido injustificado en el procedimiento en cita, no podría ya realizar un diferente planteamiento en el juicio ordinario en el cual sólo quedaría esperar una condena al pago de la indemnización demandada.

Por esto, nosotros consideramos por un lado improcedentes la insumisión al arbitraje y el no acatamiento del laudo, y por otro, inconveniente el procedimiento paraprocesal descrito para solicitar a las Juntas de Conciliación y Arbitraje o tribunales laborales, se exima al patrón de la obligación de reinstalar a los trabajadores despedidos sin justa causa, ello sin dejar de reconocer su procedencia en otros conflictos de trabajo o en diversas diligencias, sin entrar al estudio de dichos conflictos o supuestos previstos para los procedimientos paraprocesales, por no ser materia de nuestro presente trabajo.

Nosotros sostenemos, en una correcta técnica jurídica y analizados los contextos en los cuales se desarrolla el derecho patronal para ser eximido de la obligación de restablecer el derecho de la estabilidad en el empleo de los trabajadores despedidos, como primer requisito para la procedencia de dicha exención la existencia de un laudo o resolución emitidos por las Juntas de Conciliación y Arbitraje o los tribunales del trabajo cuya condena sea la reinstalación como consecuencia de un despido injustificado, pues no se puede eximir del cumplimiento de una obligación sin haber sido previamente determinada.

Por tanto, la forma correcta por medio de la cual se debe solicitar se exima a la patronal de la obligación de cumplir con el contrato de trabajo, es mediante un incidente innominado, al cual nosotros denominaremos "incidente de exención y pago compensatorio de la obligación de cumplimiento 
de contrato"; cuyo planteamiento debe realizarse al haber causado ejecutoria la condena a reinstalar a los trabajadores en sus puestos de trabajo, sin aceptar de ningún modo razonamientos o planteamientos jurídicos tendientes al no acatamiento de la resolución emitida por la autoridad jurisdiccional correspondiente.

En dicho incidente, los hechos motivo de la pretensión deben ser narrados para ubicar al trabajador ganador de la contienda en alguno de los supuestos del artículo 49 de la Ley Federal del Trabajo, sin perder de vista los hechos ya acreditados en la secuela del juicio de donde se desprenda la categoría y funciones de la parte trabajadora, así como su antigüedad en la fuente de trabajo, elementos necesarios para emitir el fallo interlocutorio correspondiente; los cuales, una vez probados, obliga a la autoridad laboral a eximir de la obligación patronal para cumplir con el contrato de trabajo sin lugar a resolver en forma contraria.

\section{CONCLUSIONES}

La estabilidad en el empleo es un derecho de los trabajadores para conservar su trabajo durante todo el tiempo pactado o determinado en la ley para la duración de la relación de trabajo, pudiendo perderlo sólo si existe una causa legalmente justificada para la rescisión sin responsabilidad para el patrón. Por tanto, este derecho se adquiere desde el momento mismo del nacimiento de la relación de trabajo.

La reinstalación en el puesto de trabajo de los operarios injustificadamente despedidos es un medio de reparación a la violación del derecho a la estabilidad en el empleo, por medio del cual se restablece el derecho violado y como consecuencia las condiciones de trabajo, brindando a los trabajadores continuidad en su relación de trabajo y en los beneficios derivados de ella.

La reinstalación de los trabajadores despedidos de forma injustificada es por regla general obligatoria, y por excepción el patrón tendrá derecho a ser eximido de la obligación de cumplir con el contrato de trabajo en los supuestos expresamente previstos en el artículo 49 de la Ley Federal del Trabajo, conmutándose dicha obligación con los pagos compensatorios previstos en el artículo 50 de dicha ley.

Consideramos necesario invertir los alcances de los supuestos normativos contenidos en el artículo 49 de la Ley Federal del Trabajo para constituir como regla general el derecho patronal para ser eximido de la obligación de 
cumplir con el contrato de trabajo, considerando casos de excepción en los cuales la reinstalación en el puesto de trabajo deba ser obligatoria.

El procedimiento jurídico por medio del cual el patrón puede ser eximido de la obligación de cumplir con el contrato de trabajo, es el incidente al cual denominamos "incidente de exención y pago compensatorio de la obligación de cumplimiento de contrato” y no así por medio de la insumisión al arbitraje, el no acatamiento de la resolución ni el procedimiento paraprocesal contenidos en la Ley Federal del Trabajo.

\section{BIBLIOGRAFÍA}

Aguilar Morales, Luis María, La relación y el contrato de trabajo, México, 2018, vol. 2.

Buen Urbina, Carlos de, Análisis de la Ley Federal del Trabajo. Comentarios y jurisprudencia, México, Porrúa, 2017.

CAPÓN FILAS, Rodolfo y GIORLANDINI, Eduardo, Diccionario de derecho social. Derecho del trabajo y la seguridad social. Relación individual del trabajo, México, UNAM/Instituto de Investigaciones Jurídicas, 2016; disponible en bttps:/ / biblio.juridicas.unam.mx/bjv/, consultado el 11 de noviembre de 2018.

Cueva, Mario de la, El nuevo derecho mexicano del trabajo. Historia, principios fundamentales, derecho individual y trabajos especiales, $15^{a}$ ed., México, Porrúa, 1998, t. I.

DÁvalos Morales, José, Tópicos laborales. Derecho individual, colectivo y procesal. Trabajos especificos. Seguridad social. Perspectivas, $4^{a}$ ed., México, Porrúa, 2006.

FERnÁndez ARras, Arturo, Selección de temas. Derecho individual del trabajo, México, Barra Nacional de Abogados, 2006.

Lagos del Campo vs. Perú, Corte Interamericana de Derechos Humanos, sentencia, excepciones preliminares, de fondo, reparaciones y costas, serie C, no. 340, Costa Rica, 31 de agosto de 2017.

Suprema Corte de Justicia de la Nación, Constitución Política de los Estados Unidos Mexicanos, texto original, México, 5 de febrero de 1917; disponible en https:// wnm.scjn.gob.mx/sites/default/files/pagina-micrositios/docu mentos/2016-12/00130029.pdf, consultado el 8 de enero de 2021.

Suprema Corte de Justicia de la NACión, Decreto que reforma el artículo 123 de la Constitución Política de los Estados Unidos Mexicanos, México, 21 de noviembre de 1962; disponible en https://mmw.scjn.gob.mx/ 
sites/default/files/cpeum/decretos_reformas/2016-12/00130081.pdf, consultado el 8 de enero de 2021.

TESIS 2a./J. 15/2018 (10a.), Semanario Judicial de la Federación y su Gaceta, décima época, t. I, libro 51, febrero de 2018.

TESIS I.6o.T. J/98, Semanario Judicial de la Federación y su Gaceta, novena época, t. XXX, septiembre de 2009.

TESIS I.1o.T.24 L, Semanario Judicial de la Federación y su Gaceta, novena época, t. II, diciembre de 1995.

TESIS 2a./J. 163/2006, Semanario Judicial de la Federación y su Gaceta, novena época, t. XXIV, diciembre de 2006. 